\title{
Characteristics of lightning flashes generating sprites above storms
}

\author{
Serge Soula ${ }^{1}$, Oscar van der Velde ${ }^{2}$, Joan Montanya ${ }^{2}$, Martin Fullekrug ${ }^{3}$, \\ Andrew Mezentsev ${ }^{3}$, and Janusz Mlynarczyk ${ }^{4}$ \\ ${ }^{1}$ Laboratoire d'Aérologie, Université de Toulouse, CNRS, Toulouse, France \\ ${ }^{2}$ Electrical Engineering Department, Technological University of Catalonia, Terrassa, Spain \\ ${ }^{3}$ University of Bath, Department of Electronic and Electrical Engineering, Bath, UK \\ ${ }^{4}$ Department of Electronics, AGH University of Science and Technology, Krakow, Poland
}

\begin{abstract}
Sprites are Transient Luminous Events (TLEs) that can extend vertically from 40 to $90 \mathrm{~km}$ and horizontally over several tens of $\mathrm{km}$ to form clusters of individual or multiple column or/and carrot-shaped luminous elements. They can even extend over more than $100 \mathrm{~km}$ in the form of sequential luminous emissions that are called "dancing sprites". Their optical detection and other parameters describing the storm and the lightning activity associated allow us to understand the conditions of their production and their links with the lightning activity. Our observations confirm some characteristics of the sprites and put forward others: (i) the sprites are essentially produced above the stratiform region of the Mesoscale Convective Systems after positive cloud-to-ground lightning flashes that produce large Charge Moment Change (CMC), with a shorter delay if the impulsive CMC (iCMC) is larger. (ii) The dancing sprites reflect the timing and the location of the successive lightning strokes that generate them. (iii) The sprite elements can be shifted from the stroke location when their delay is large. (iv) Bright sprites produce current signatures in ELF radiation a few milliseconds $(<5 \mathrm{~ms})$ after the positive strokes that generate them.
\end{abstract}

\section{Introduction}

Sprites constitute a type of Transient Luminous Events (TLEs) often observed since the first dedicated campaigns in the US [1-3]. They have various shapes structure of streamers that classify them in several types, e.g., columnar, carrot, jellyfish, angel... [4-7]. Sprites can also horizontally extend over several tens of $\mathrm{km}$ in the form of sprite clusters [3,8,9] and they can even occur over more than $\sim 100 \mathrm{~km}$ in the form of sequential luminous emissions that are called "dancing sprites" $[10,11]$.

Most of the time, sprites occur above stratiform regions of Mesoscale Convective Systems (MCS), shortly after sprite-producing positive cloud-to-ground ( $\mathrm{SP}+\mathrm{CG}$ ) strokes that lower a large amount of charge to the ground [2,12-14]. Thus, after the SP+CG stroke, the sprite discharge develops as a streamer as a result of the strong transient electrostatic field that exceeds the threshold for dielectric breakdown in the middle atmosphere, generally around $70 \mathrm{~km}[15]$. The time delay after the lightning stroke ranges from a few ms to several tens of ms $[13,16]$; the time delay depends on the characteristics of the SP+CG stroke, especially in terms of CMC, iCMC and current waveforms [17]. It can reach a few tens of ms after a long lightning continuing current following the stroke [18].

Generally, the SP+CG flashes start close to the convective cores of the storm and horizontally extend into stratiform region that consists of several layers of alternating charge 
polarity at different altitudes. These flashes supposedly follow trajectories of charged ice particles toward the stratiform region of the storm system [19, 20]. Some of these flashes can be considered as spider lightning [21, 22]. In a recent work [20] the authors identified different modes of evolution of the negative leaders throughout the thundercloud system that can explain the positioning and timing of the positive $+\mathrm{CG}$ strokes. Thus, the negative leaders may propagate at various altitudes with different velocities and over various distances, while generating several multiple + CG strokes.

This paper summarizes the characteristics of the lightning flashes that produce sprites and the different links between both. Data from several case studies enable us to illustrate the findings collected during the last years in this contribution.

\section{Data}

The videos used in this study are recorded with low-light Watec $902 \mathrm{H}$ cameras oriented to the storm with a pan-tilt unit that can be remotely controlled via the Internet [17]. They operate in a triggered mode provided by the UFOCaptureV2 software from Sonotaco Company, to capture luminous events with brightness above a given threshold. The obtained video imagery has a time resolution of 25 frames (or 50 interlaced fields) per second, which corresponds to a time resolution of 20 milliseconds. The video camera also records GPS-referenced time and inserts the time in each video frame. The azimuth and elevation of the sprite events are determined with the software "Cartes du Ciel" (SkyCharts) by overlaying known stars on an image from the video imagery.

Lightning location systems monitor the lightning flash activity and provide most of $\mathrm{SP}+\mathrm{CG}$ strokes within the studied area. The European lightning detection network operated by European Cooperation for Lightning Detection (EUCLID) records CG flash characteristics such as the location, polarity, peak current, and the occurrence times of CG strokes. The sensors of the network use both magnetic direction finding (MDF) and time of arrival (TOA) techniques to determine the location of CG strokes [18]. The detection efficiency (DE) of this network is $\sim 90 \%$ over land and close to the coastline. The total lightning activity can be documented in restricted areas, as for example in Catalonia with the Lightning Mapping System XDDE operated by the Meteorological Service of Catalonia (SMC). During the field experiment of HyMeX at the Fall 2012, a Lightning Mapping Array was installed in southeastern France [17]. These systems detect and locate very high frequency (VHF) sources produced by different sections of a lightning leader, by interferometry for one and by difference of time of arrival for the other.

A system located at University of Bath $(51.71 \mathrm{~N} ; 2.32 \mathrm{~W})$ records broadband $\mathrm{ELF} / \mathrm{VLF} / \mathrm{LF} / \mathrm{MF}$ electromagnetic waves. It consists of a metal plate insulated from the ground to measure the vertical electric field, a precise GPS clock for timing the data acquisition, and an analogue signal conditioning and digital data acquisition unit [23]. This instrument has the capability to record electric field magnitudes in the frequency range from approximately $\sim 4 \mathrm{~Hz}$ to $\sim 400 \mathrm{kHz}$ with a sampling frequency of $1 \mathrm{MHz}$, an amplitude resolution of $\sim 35 \mu \mathrm{V} \mathrm{m}^{-1}$, and a timing accuracy of $\sim 10-20 \mathrm{~ns}$.

The charge moment change (CMC), the impulsive CMC (iCMC) and the current moment waveform associated with the CG flashes [13] are reconstructed from ELF receiver measurements, by using the method presented by Mlynarczyk et al. [24]. The ELF recordings are performed by the Hylaty ELF station in Poland [25].

Reflectivity from meteorological radar is used to describe the structure of the storm. 24 Doppler radars ( $\mathrm{C}$ band and $\mathrm{S}$ band) cover the entire area of mainland France and according to the location of the storm system analyzed, data from several radars can provide the $3 \mathrm{D}$ fields of radar reflectivity every 15 minutes up to a height of $14 \mathrm{~km}$ amsl. The 

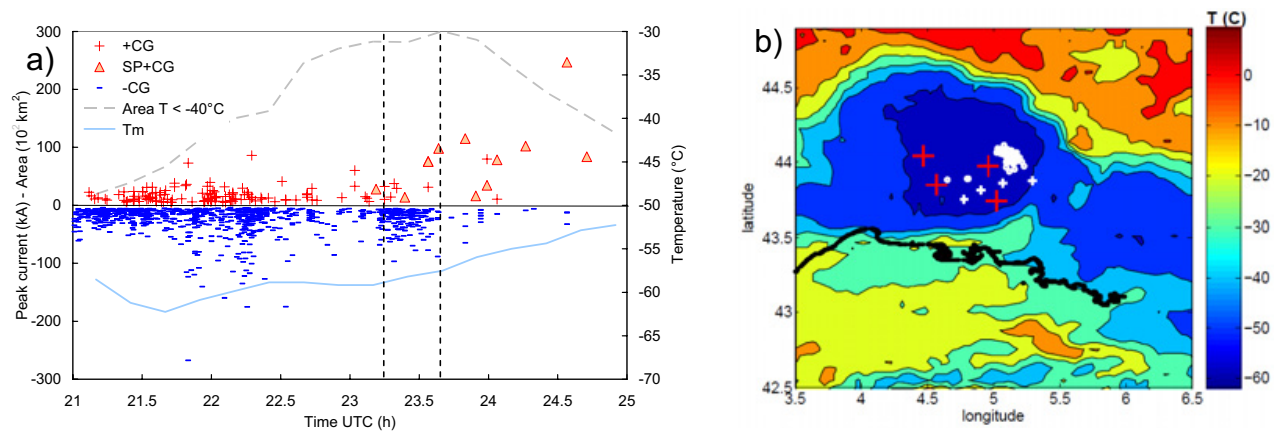

Figure 1. a) Time series of the peak current of $+\mathrm{CG}, \mathrm{SP}+\mathrm{CG}$ and $-\mathrm{CG}$ strokes, minimum temperature of the cloud top $\mathrm{Tm}$, and of the cloud area with a temperature $\mathrm{T}<-40{ }^{\circ} \mathrm{C}$ for the storm on October $22^{\text {nd }}$ of 2012. b) Distribution of the cloud top temperature in the area of the storm at 2325 UTC and location of the $+\mathrm{CG}$ (white cross), SP+CG (red plus) and -CG (white circle) strokes between 2315 and 2335 UTC.

horizontal (resp. vertical) resolution of reflectivity fields is $1 \mathrm{~km}$ (resp. $0.5 \mathrm{~km}$ ). The cloud top temperatures are provided by the Meteosat satellite from European Organization for the Exploitation of Meteorological Satellites (EUMETSAT). Meteosat Second Generation (MSG) Spinning Enhanced Visible and Infrared Imager (SEVIRI) is based on radiometer data in the thermal infrared band (IR) at 11-13 $\mu \mathrm{m}$. The parallax error is taken into account for the plots which associate the locations of $\mathrm{CG}$ strokes and their parent clouds.

\section{Sprite and storm activity}

The activity and the sprites produced by a storm in southeastern France on October $22^{\text {nd }}$, 2012, could be monitored during its whole lifetime. Two cameras allowed us to detect 12 sprite events and several lightning detection systems provided the total lightning activity, especially thanks to a LMA operated during the HyMeX campaign [17]. The storm is classified as a MCS with an activity of $\sim 4$ hours. Figure 1a displays the time series of the CG strokes characterized by their peak current, the size of the storm system (area $\mathrm{T}<-40^{\circ} \mathrm{C}$ ) and the minimum value of the cloud top temperature. The SP+CG strokes occur during the last third of the storm activity and start when the CG flash rate decreases drastically, the size of the system is maximum and well after the minimum of the cloud top temperature (CTT), i.e. after the strong convection. All strokes preceding a sprite are positive $(\mathrm{SP}+\mathrm{CG})$ and their peak current is much larger in average than that of the other $+\mathrm{CG}$ strokes. Figure $1 \mathrm{~b}$ displays the distribution of the CTT at 2325 UTC and the location of the lightning strokes detected between 2315 and 2335 UTC, including four SP+CG strokes. The latter are spatially separated from most $-\mathrm{CG}$ strokes that cluster in a specific area corresponding to the convective region [17]. Thus this sample confirms the typical location of the SP+CG strokes within the stratiform region of the MCS.

\section{Sprite and lightning geometry}

Figure 2 displays a case of lightning flash producing a sprite triangulated from two cameras detections (Fig. 2c) during the storm described in Sect. 3. In Fig. 2a and 2b, the VHF sources localized in 3D thanks to a LMA are plotted versus time with the longitude and the altitude, respectively. Figure $2 \mathrm{~d}$ displays their $2 \mathrm{D}$ location within the storm system characterized by the radar reflectivity at $3000 \mathrm{~m}$ altitude. The flash starts close to the large reflectivity of the 


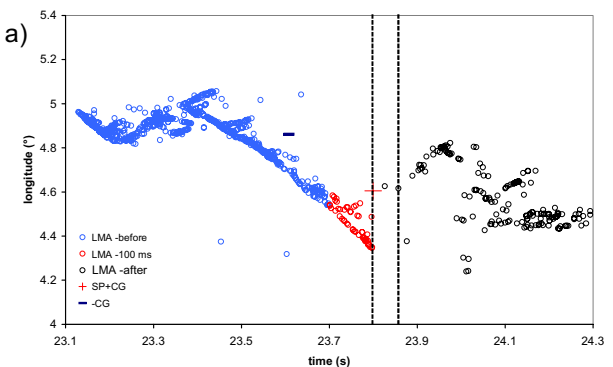

c)
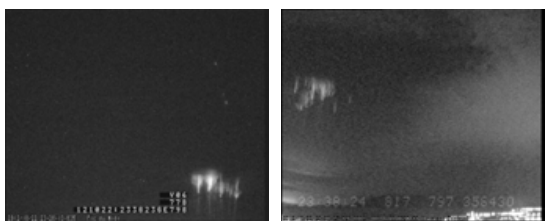

d)
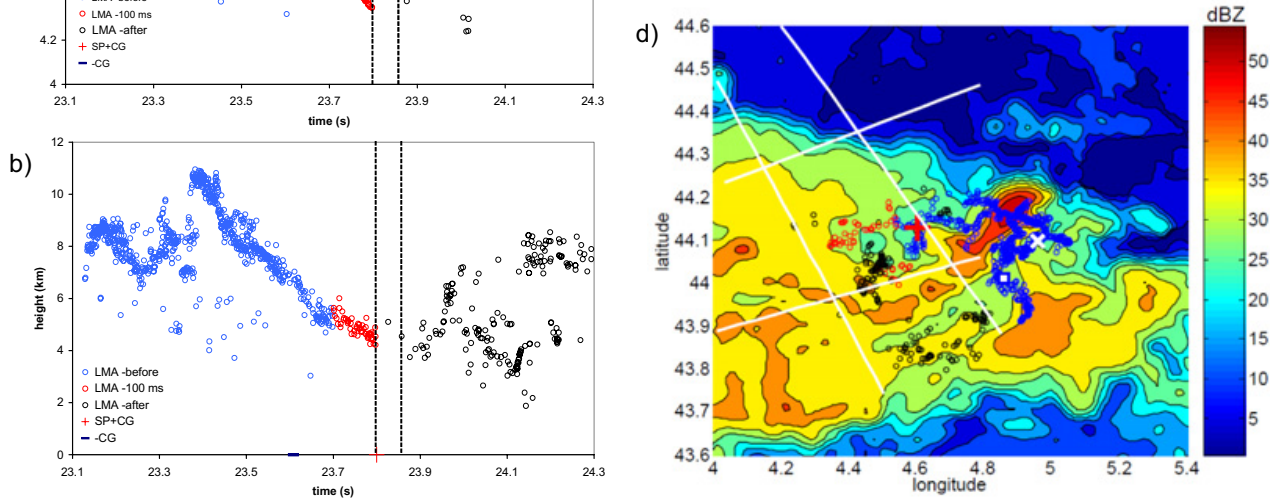

Figure 2. a) and b) Time series of the longitude and the altitude of the LMA-detected VHF sources (blue/red/black for at least $100 \mathrm{~ms}$ before/less than $100 \mathrm{~ms}$ before/after sprite event) and Euclid-detected CG strokes, after 2323 UTC. c) Two frames of the same sprite issued from two cameras at $\mathrm{t}=23.798 \mathrm{~s}$ and $\mathrm{t}=23.797 \mathrm{~s}$, respectively. Distribution of the CTT in the area of the storm at $2325 \mathrm{UTC}$ and location of the +CG (white cross), SP+CG (red plus) and -CG (white circle) strokes between 2315 and 2335 UTC. (d) Radar reflectivity field at the altitude of $3000 \mathrm{~m}$ at 2345 UTC, with superimposed the same events of the lightning activity as in a) and b). The white cross indicates the first VHF source detected and the white lines display the lines of sight of the main sprite elements.

convective region (white cross), remains in the same area for $\sim 0.25 \mathrm{~s}$ and propagates westerly to develop its main branch (blue dots) at an altitude lower and lower across the stratiform region. It continues its propagation at a speed $\sim 1.510^{5} \mathrm{~m} \mathrm{~s}^{-1}$, typical of a negative leader, until the sprite triggers (red dots). The SP+CG stroke (red plus) is located at the rear of the leader, within the stratiform region and within the same video frame (white lines in Fig. 2d) that is used for the triangulation of the sprite cluster.

\section{Sprite and lightning chronology}

A case of dancing sprite was detected during a storm on October $29^{\text {th }}$ of 2013 , over the Mediterranean Sea in the region of Balearic Islands. This sprite was especially long in time with four sequences of light emission, each one associated with a SP+CG stroke, as illustrated in Fig. 3b. Indeed, the sequences are indicated with horizontal lines that correspond to the four sequences illustrated with two frames for each in Fig. 3a. The peak current indicates the occurrence of the SP+CG strokes that coincide exactly with the beginning of the sequences, except for the first one with a long time-delayed sprite $(\sim 70 \mathrm{~ms})$. Figure $3 \mathrm{~b}$ displays other information of lightning activity, especially IC activity (cross at an arbitrary value of $100 \mathrm{kA}$ ) that occurs either during or before the sprite sequences. The electric field radiated in the VLF/LF range corresponds to the $\mathrm{SP}+\mathrm{CG}$ strokes (Fig. 3c).

\section{Sprite and lightning current waveform}

The $\mathrm{SP}+\mathrm{CG}$ strokes can be characterized by the peak current as it is seen in the previous sections, but also by the CMC, the iCMC and the current moment waveform. This information 
a)
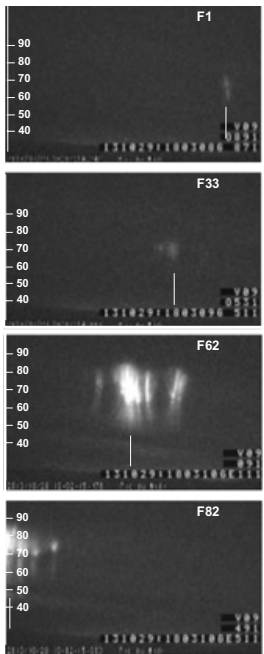
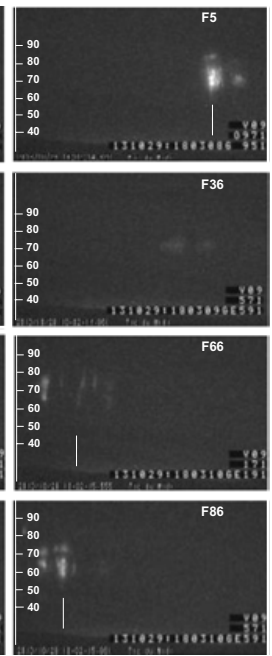
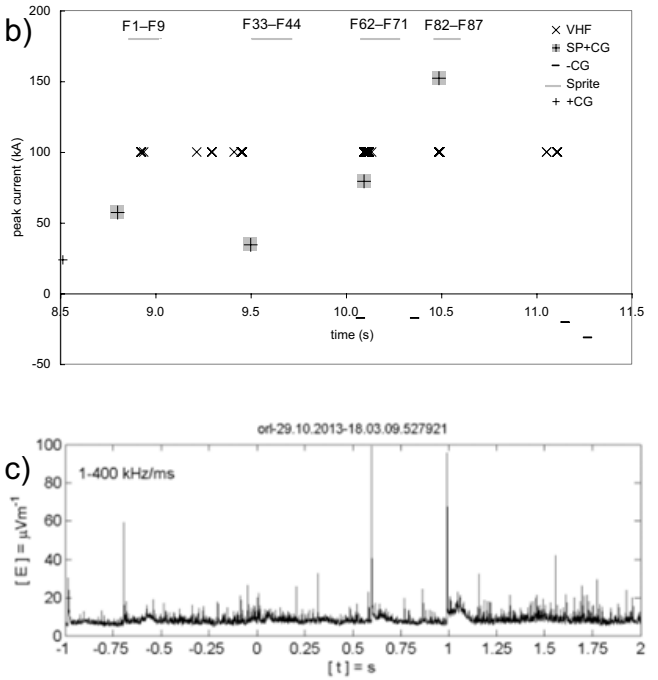

Figure 3. Case of dancing sprite at 1803 UTC on October $29^{\text {th }}$ of 2013: a) 8 specific frames issued from the video imagery numbered from F1 that is the first frame with sprite luminosity. (b) Peak current versus time for 3 seconds for $-\mathrm{CG}$ strokes (black minus), + CG strokes (black plus), SP+CG strokes (large plus) and IC strokes plotted with an arbitrary current value of $100 \mathrm{kA}$ (black cross). Four sequences of sprite luminosity are indicated with grey lines and frame numbers. (c) Electric field radiated in VLF/LF range for the same period of 3 seconds $(t=0$ corresponds to $t=9.528 \mathrm{~s}$ in upper graph).
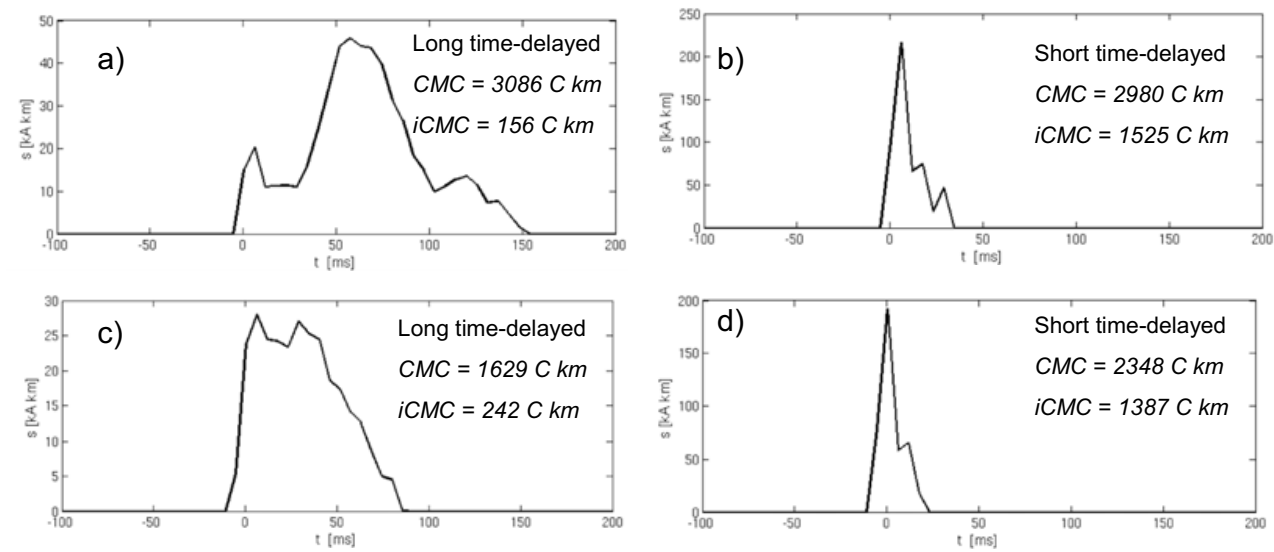

Figure 4. Current moment waveform for $4 \mathrm{SP}+\mathrm{CG}$ strokes recorded on October $22^{\text {nd }}$ of 2012: a) and c) correspond to long-delayed time sprites; b) and d) correspond to short-delayed time sprites. The time $\mathrm{t}=0$ corresponds to the $\mathrm{SP}+\mathrm{CG}$ stroke detection.

describes how the charge is lowered in the lightning channel. The graphs of Fig. 4 display four cases of $\mathrm{SP}+\mathrm{CG}$ strokes that illustrate the observations made in different cases of storms. a) and c) correspond to long time-delayed sprites while b) and d) correspond to short timedelayed sprites. Furthermore, b) and d) correspond to bright sprites. Thus, it is observed that the $+\mathrm{CG}$ strokes with a low iCMC can lead to a sprite emission but with a long delay that allows more charge to be neutralized during the lightning process. The short time-delayed sprites are triggered by $\mathrm{SP}+\mathrm{CG}$ strokes with a strong iCMC, i.e. a large amount of charge is 
rapidly neutralized by the lightning process. In all cases of sprites, the CMC of the lightning stroke has a value above a threshold of a few hundreds of $\mathrm{C} \mathrm{km}$. The brightness of the sprites also seems to depend on the iCMC of the parent stroke.

\section{Conclusion}

Several case studies of sprite-producing storms allow us to characterize the SP+CG strokes, and in a more comprehensive way, the flashes that include them. The sprite-producing lightning strokes are positive and located in the stratiform region of the storm. They occur at the end of the storm activity when the stratiform region is well developed. The SP+CG flashes start generally close to the convective region and follow long paths across the stratiform region. The SP+CG strokes produce large CMCs, while their iCMC can be either low and the sprites occur after a long delay, or large and the sprites occur rapidly and very bright. Dancing sprites are produced by successive SP+CG strokes or pulse currents associated with the lightning process (continuing current, $\mathrm{M}$ component...). The bright sprite can provide a substantial contribution to the current signature.

\section{References}

[1] D.D. Sentman, E.M. Wescott, Geophys. Res. Lett. 20, 24 (1993).

[2] W.A. Lyons, J. Geophys. Res., 101, D23 (1996).

[3] D.D. Sentman, E.M. Wescott, D.L. Osborne, D.L. Hampton, M.J. Heavner, Geophys. Res. Lett., 22, 10 (1995).

[4] W.A. Lyons, T.E. Nelson, E.R. Williams, S.A. Cummer, M.A. Stanley, Mon. Weather Rev., 131, 2417 (2003).

[5] H.C. Stenbaek-Nielsen, M.G. McHarg, J. Phys. D Appl. Phys., 41, 234009 (2008).

[6] J. Li, S.A. Cummer, Geophys. Res. Lett., 36, L10812 (2009).

[7] J. Montanyà, O. van der Velde, D. Romero, V. March, G. Solà, N. Pineda, M. Arrayas, J.L. Trueba, V. Reglero, S. Soula, J. Geophys. Res., 115, A00E18 (2010).

[8] M. Füllekrug, D.R. Moudry, G. Dawes, and D.D. Sentman, J. Geophys. Res., 106, D17 (2001).

[9] S. Soula, F. Iacovella, O. van der Velde, J. Montanyà, M. Füllekrug, T. Farges, J. Bór, J.-F. Georgis, S. NaitAmor, J.-M. Martin, Atmos. Res., 135, 415-431 (2014).

[10] J.R. Winckler, W.A. Lyons, T.E. Nelson, R.J. Nemzek, J. Geophys. Res., 101, D3 (1996).

[11] M. Füllekrug, A. Mezentsev, S. Soula, O. van der Velde, T. Farges, Geophys. Res. Lett., 40, 2395-2399 (2013).

[12] D.J. Boccippio, E.R. Williams, S.J. Heckman, W.A. Lyons, I. Baker, R. Boldi, Science, 269, 1088-1091 (1995).

[13] S.A. Cummer, W.A. Lyons, J. Geophys. Res., 110, A04304 (2005).

[14] S. Soula, O. van der Velde, J. Montanyà, T. Neubert, O. Chanrion, M. Ganot, Atmos. Res., 91, 2-4 (2009).

[15] V.P. Pasko, U.S. Inan, T.F. Bell, Y.N. Taranenko, J. Geophys. Res., 102, A3, 4529 (1997).

[16] O.A. van der Velde, Á. Mika, S. Soula, C. Haldoupis, T. Neubert, U.S. Inan, J. Geophys. Res., 111, D15203 (2006).

[17] S. Soula, et al., J. Geophys. Res. Atmos., 120, 11,552 (2015).

[18] S.A. Cummer, M. Füllekrug, Geophys. Res. Lett., 28, 3 (2001).

[19] L.D. Carey, M.J. Murphy, T.L. McCormick, N.W.S. Demetriades, J. Geophys. Res., 110, D03105 (2005). 
[20] O.A. van der Velde, J. Montanya, S. Soula, N. Pineda, J. Mlynarczyk, J. Geophys. Res. Atmos., 119 (2014).

[21] V. Mazur, X. Shao, P.R. Krehbiel, J. Geophys. Res., 103, D16 (1998).

[22] T.J. Lang, S.A. Rutledge, K.C. Wiens, Geophys. Res. Lett., 31, L10105 (2004).

[23] M. Füllekrug, Meas. Sci. Technol., 21 (2010).

[24] J. Mlynarczyk, J. Bór, A. Kulak, M. Popek, J. Kubisz, J. Geophys. Res. Space Physics, 120, 2241 (2015).

[25] A. Kulak, J. Kubisz, S. Klucjasz, A. Michalec, J. Mlynarczyk, Z. Nieckarz, M. Ostrowski, S. Zieba, Radio Sci., 49, 361 (2014). 